\title{
La publicidad de productos de belleza femenina en Costa Rica (1900-1930)
}

\section{Virginia Mora Carvajal ${ }^{2}$}

Recepción: 8 de octubre de 2016 / Aprobación: 26 de febrero de 2017

\section{Resumen}

Este trabajo estudia un tema poco explorado en el contexto costarricense, la belleza femenina desde la perspectiva de la publicidad impresa. En tal sentido, se propone determinar los principales productos de belleza publicitados en la prensa costarricense en el período 1900-1930, con el fin de establecer las características de este tipo de publicidad y las concepciones de belleza que en ellos se presentan, así como su incidencia en la construcción de un modelo de feminidad costarricense en la primera mitad del siglo XX. Para ello se consultan los periódicos de la época y se sistematizan los anuncios publicitarios en una serie de categorías por tipo de producto. En los resultados de la investigación destaca el colocar el tema de la belleza femenina como un asunto de interés académico, cuyas implicaciones se manifiestan en el campo económico, político y social, vinculadas con las concepciones de la belleza y el control del cuerpo de las mujeres.

\section{Palabras clave}

Publicidad; mujeres; belleza femenina; feminidad; género

\section{Abstract}

This article studies a little explored subject in the Costa Rican context: feminine beauty from the perspective of print advertising. In this regard, it identifies the main beauty products advertised in the Costa Rican press in the period 1900-1930, in order to establish the characteristics of this type of advertising, the conceptions of beauty that they reflect, as well as their impact in the construction of the Costa Rican femininity in the first half of the twentieth century. In order to do so, the newspapers of the time are consulted and advertisements are systematized in a number of categories by product type. The research's results place the issue of female beauty as a matter of academic interest, with implications that are manifest in the economic, political and social fields and linked to the concepts of women's beauty and the control of their body.

\section{Keywords}

1 La autora agradece los comentarios y sugerencias realizados por la Dra. Vanessa Fonseca a una primera versión de este trabajo. Asimismo, reconoce la asistencia de Nicole Fonseca Masís y Diana Carrillo Rosales, estudiantes de la Escuela de Ciencias de la Comunicación Colectiva, en la recopilación de la información para este estudio.

2 Costarricense. Máster en Historia. Docente de la Escuela de Ciencias de la Comunicación Colectiva e investigadora del Centro de Investigación en Comunicación de la Universidad de Costa Rica (UCR). Correo electrónico: vmora@ice.co.cr 
Advertising; women; female beauty; femininity; gender

\section{Resumo}

Este trabalho estuda um tema pouco explorado no contexto costarriquenho, como é o da beleza feminina a partir da perspectiva da publicidade impressa. Nesse sentido, se propõe determinar os principais produtos de beleza publicitados na imprensa costarriquenha no período 1900-1930, com o intuito de estabelecer as características deste tipo de publicidade e as concepções de beleza que se apresentam neles, assim como sua incidência na construção da feminilidade costarriquenha na primeira metade do século XX. Para tanto, se consultam os jornais da época e se sistematizam os anúncios publicitários em uma série de categorias por tipo de produto. Nos resultados da pesquisa, se destaca a colocação do tema da beleza feminina como um assunto de interesse acadêmico, cujas implicações se manifestam no campo econômico, político e social, vinculadas com as concepções da beleza e o controle do corpo das mulheres.

\section{Palavras chave}

Publicidade; mulheres; beleza feminina; feminilidade; gênero

En noviembre de 1920, el panameño Julio Guardia de visita por San José, hace unas interesantes manifestaciones acerca de la belleza de las mujeres costarricenses, las cuales son publicadas en el Diario de Costa Rica, en un artículo titulado "Es muy elogiada la hermosura de la costarricense". De dichas manifestaciones interesa reproducir el siguiente texto:

La belleza de la mujer tica es indiscutible: en esto todos los viajeros estamos absolutamente de acuerdo.

La mujer costarricense puede compararse con la francesa por su elegancia en el vestir, su refinamiento, su gracia en el andar, su feminismo, su chic y donde mejor puede apreciarse la hermosura y gracia de la mujer costarricense, es en las retretas del Parque Central de San José y en el Teatro Nacional, uno de los más lujosos del mundo, en una noche de gala. Qué mujeres más guapas! Qué beldades se ven allí! Y las hay de todos los gustos: al lado de un soberbio ángel de cabellera de azabache y dos hogueras por ojos, no es extraño ver a un querubín con una cascada de oro sobre su cabeza y con ojos profundos y azules como los lagos suizos, soñadores, y de mirada lánguida.

Pero lo que más llama la atención no es tanto la belleza de las ticas como el número de mujeres guapas. Pasa una, pasan dos, cuatro, cincuenta, cien... y unas son apenas guapas, otras bonitas, otras arrebatadoras, pero ninguna fea...

A San José se le podría llamar muy bien, por la gracia, el chic, el feminismo y la belleza de sus mujeres, 'Le Petit Paris de l'Amérique Centrale'.

Y qué decir de las mujeres que asisten a las funciones del Nacional? Sencillamente que son divinas (Diario de Costa Rica, 17 de noviembre de 1920, p. 3).

Si bien la belleza de las costarricenses es objeto de admiración para el visitante y, como él mismo lo apunta, es algo "indiscutible", tanto este tema como el de los modelos de belleza que históricamente han predominado en 
uno $u$ otro periodo, no han sido objeto de una investigación sistemática en nuestro país, ello debido, en parte, a que se trata de un tema considerado superficial, vinculado al mundo de la moda y el de los cosméticos, sin mayores implicaciones para el desarrollo de la sociedad. No obstante, es contenido con consecuencias importantes, no solo para las mujeres -en tanto sujetas básicas de toda una serie de productos y servicios que ofrecen su embellecimiento físico-, sino también para la sociedad en general, en la medida en que la presión que experimentan muchas mujeres por alcanzar los patrones de belleza socialmente establecidos pueden llegar a límites que ponen en riesgo su salud e incluso su vida.

Aunado a lo anterior, la belleza se ha transformado en un negocio muy lucrativo, ligado estrechamente al campo de la publicidad, al poner a disposición de las mujeres una amplia gama de bienes, cuyo objetivo es volverlas más bellas, atractivas y jóvenes, aspiración que ha estado presente en el caso de la publicidad impresa costarricense desde las primeras décadas del siglo XX (Vega, 2008).

Desde esa perspectiva, este trabajo se propone determinar los principales productos de belleza femeninos publicitados en el período 1900-1930; establecer las características de la publicidad de este tipo de productos y, finalmente, relacionarla con las concepciones de feminidad imperantes en Costa Rica y en el ámbito internacional durante las primeras décadas del siglo XX. Asimismo, son varias las preguntas de investigación que guían este trabajo. Entre ellas: ¿Qué significa ser una mujer "bella" en Costa Rica entre 1900 y 1930? ¿Cómo contribuye la publicidad a construir la belleza femenina en la sociedad costarricense de ese período? ¿Cuáles son los productos de belleza que más se anuncian? ¿Qué partes del cuerpo femenino son particularmente importantes como objeto de belleza? ¿Existían parámetros de belleza internacionales que influyeron en la publicidad costarricense y, por ende, en la concepción de la belleza femenina?

En tal sentido, este trabajo estudia la publicidad impresa costarricense de productos de belleza dirigidos a mujeres entre 1900 y 1930, a partir de cuatro aspectos fundamentales: los productos de belleza publicitados; el uso de la imagen femenina; las partes del cuerpo de la mujer que se destacan y las concepciones de belleza que propone la publicidad de este tipo de productos. De igual forma, se busca enmarcar esta investigación en el contexto de las características de la condición femenina en la Costa Rica de la época y del desarrollo de la publicidad en el ámbito internacional.

Para ello se consultaron 13 periódicos del periodo, de los que se obtuvo una muestra de 625 anuncios publicitarios, cuya distribución por periódico se presenta en el Gráfico 1. Cabe apuntar que si bien a la fecha estos periódicos se encuentran digitalizados en el portal de la Biblioteca Nacional (SINABI, http://www.sinabi.go.cr/), cuando esta investigación inició, todavía dicho pro- 
ceso estaba en marcha, por lo que el acceso a muchos de los periódicos era restringido. Ello explica -en buena medida- la desigual cantidad de anuncios recopilados entre los distintos periódicos, entre los que predomina el Diario de Costa Rica, el cual pudo ser revisado en su totalidad para la década de 1920, gracias al acceso digital de sus ejemplares en el portal citado. Es importante aclarar que, si bien en la actualidad estos 13 periódicos se encuentran digitalizados, no era viable ni factible, en términos de la investigación, volver a revisarlos, por lo que se utilizan los anuncios que en su momento pudieron ser recopilados.

\section{Gráfico 1}

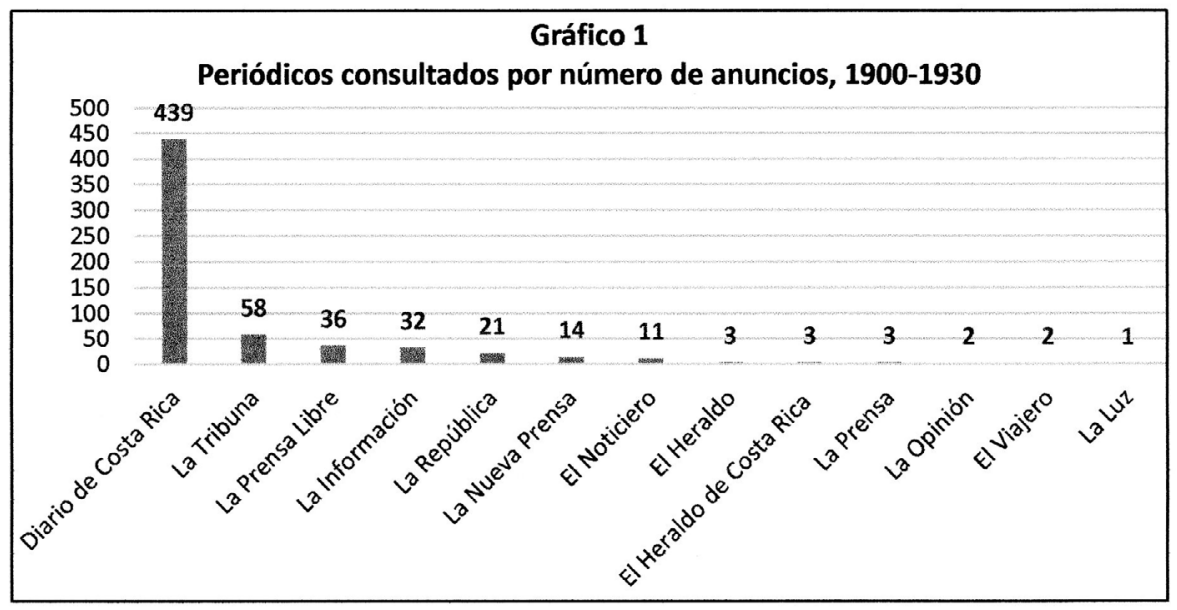

Fuente: Elaboración propia con base en los anuncios recopilados de los periódicos costarricenses durante 1900-1930.

Ahora bien, dada la cantidad de anuncios recopilada, para este trabajo se van a considerar solamente 397 publicaciones que corresponden a las categorías de productos de belleza destinados a las mujeres que presentan el mayor número de anuncios. Esas categorías son: productos de tocador (276 anuncios), productos para el cabello (98 anuncios) y productos para las uñas (23 anuncios). Cabe apuntar que, si bien esta es una investigación de carácter cualitativo, dada la carencia de estudios previos de base sobre el tema, era fundamental conocer los anuncios más publicitados de este tipo de productos dentro de la muestra analizada; de ahí la necesidad de cuantificar ese punto y presentar sus resultados en forma de cuadros con el propósito de permitir una mejor sistematización y una comprensión más clara de los mismos.

Adicionalmente, es importante enfatizar el hecho de que esta investigación es de carácter exploratorio, pues se busca conocer las posibilidades que ofrece el estudio de la publicidad de productos de belleza femenina, para una mayor comprensión del proceso de construcción de la feminidad costarricense en el período estudiado; de tal modo, los resultados que se ofrecen seguidamente 
pueden tener un cierto rasgo descriptivo y, aunque se procuró profundizar en la explicación de los distintos aspectos, ello no fue posible con la profundidad deseada, dado que se trata de una primera aproximación a esta temática, la cual se espera sirva de base para futuros trabajos.

El trabajo se estructura en tres apartados. En el primero, titulado Publicidad, belleza y participación de las mujeres, se hacen algunas reflexiones en torno al tema de la belleza como propuesta de investigación y se estudia la participación de las mujeres en la cultura de la belleza que surge a finales del siglo XIX y primeras décadas del XX, tomando el caso de los Estados Unidos como referencia, debido al desarrollo de este tipo de temas en ese país. En el segundo, denominado Ideales de mujer y belleza a inicios del siglo XX, se hace referencia al ideal de belleza femenina que predomina a inicios del siglo XX, considerando el caso de las llamadas "Gibson Girls"3 y del Art Decó, pues ambas tendencias influyen en la publicidad de entonces y en la representación que se hace de las mujeres en ella, como modelos o ideales de belleza femenina y de la nueva feminidad que asoma en este período. El tercer apartado lleva por título Publicidad de productos de belleza femeninos y está dedicado al análisis de los productos de belleza femeninos publicitados, de forma específica, los productos de tocador, los ofrecidos para el cuido del cabello y aquellos destinados al embellecimiento de las uñas. El trabajo concluye con las reflexiones finales.

\section{Publicidad, belleza y participación de las mujeres}

Aunque estudiar la belleza femenina puede parecer un tema superficial, un asunto de moda y, por ende, poco relevante para la sociedad en general y para las mujeres en particular, lejos está de serlo, pues la belleza es una temática que tiene relación con otros aspectos fundamentales como el desarrollo de una industria alrededor de los productos de belleza, con la capacidad de consumo y la posición socioeconómica de las mujeres -todavía las principales consumidoras de estos productos-, con el control del cuerpo por medio de productos y/o tecnologías que lo modelan, con la etnia -en el sentido de establecer cuál es el modelo de mujer que se define como bella- y, con el género, ya que finalmente el tema de la belleza contribuye a definir y/o a redefinir las concepciones imperantes de feminidad.

Desde esta perspectiva, como bien lo apunta Peiss (2011), hasta el siglo $\mathrm{XIX}$, ¿el maquillarse?, o usar cosméticos, no estaba bien visto entre las mujeres

3 Se conoce como "Gibson Girls" a una serie de ilustraciones de mujeres jóvenes elaboradas por el artista estadounidense Charles Dana Gibson, entre finales del siglo XIX y primeras décadas del XX. Estas fueron publicadas en las principales revistas de la época, la mayoría de las cuales iban dirigidas al público femenino. Dichas ilustraciones dan origen al primer ideal de belleza femenina de los Estados Unidos, cuya influencia se extiende a distintos contextos gracias, entre otros elementos, a su incidencia en la representación de la mujer en la publicidad del período. 
consideradas virtuosas y representantes fieles del modelo de feminidad en el cual el lugar de la mujer estaba en su casa, al lado de su esposo e hijos. Así, la oposición entre la "dama" y la "libertina" o la "mujerzuela" era tajante, no solo porque esta última era considerada como una "mujer de la calle", es decir, como una mujer que interactuaba en el espacio público, sino también porque era una "mujer pintada" y, por tanto, era censurada socialmente y calificada casi como "lo peor" de la feminidad, en contraste con la "dama", que representaba la mejor versión de esta.

Entonces, ¿cómo es que esta situación cambia? ¿Cómo es que el hecho de que una mujer se pinte deje de ser visto como algo propio de las mujeres "públicas"? ¿Cómo se llega a masificar el uso de los cosméticos para las mujeres? Se debe considerar que, desde la antigüedad, las mujeres han utilizado distintos tipos de productos naturales con el propósito de verse más bellas. No obstante, durante el siglo XIX, con las ideas victorianas en torno al papel de las mujeres en la sociedad y del carácter "natural" de la belleza femenina, la negación del uso de cosméticos llega a predominar entre las mujeres distinguidas o las "damas" de la sociedad, mientras que las mujeres "vulgares" o "libertinas" sí continuaron con el uso de tales productos, ya sea porque era parte de su trabajo -como en el caso de las artistas o incluso de las entonces llamadas "mujeres públicas"- o simplemente porque no se amoldaron a los requerimientos impuestos a las mujeres.

Sin embargo, con el desarrollo de la publicidad de manera más profesional, sobre todo durante la segunda mitad del siglo XIX, con el auge de las agencias de publicidad y con el surgimiento de la sociedad de consumo, en las primeras décadas del siglo XX, surge la necesidad de masificar el uso de los cosméticos y darle un nuevo sentido a su uso como parte de la nueva mujer del siglo XX; de ahí que productos elaborados artesanalmente para uso propio o comunitario, se transforman en bienes de consumo masivo por parte de la población femenina. Este proceso se relaciona con los cambios presentados en el transcurso de los siglos XIX y XX.

Desde esta perspectiva, la incipiente industria cosmética experimenta cambios cuando -producto de las ideas de modernidad relacionadas con los nuevos hábitos de higiene y limpieza que la vida urbana implicaba, como parte de los elementos básicos de la nueva estética de la época- se comienza a naturalizar el uso de productos como jabones de baño, desodorantes y pastas de dientes. Estos eran considerados indicadores de la mujer moderna, urbana y, por ende, cosmopolita y sofisticada, lo cual constituye el modelo de la mujer moderna de las primeras décadas del siglo XX y que, como se expondrá luego, representa el contexto en el cual se inscriben las "Gibson Girls” y las mujeres exóticas del Art Decó en la publicidad, en artículos como los cigarrillos, para citar solo un ejemplo (Marchand, 1986). 
En tal sentido, Peiss (2011) introduce el concepto de cultura de la belleza para tratar de comprender el cambio descrito antes, dentro del cual también las mujeres cumplen un papel importante, en especial, durante el período 1890-1920, cuando se está comenzando a desarrollar la industria cosmética en los Estados Unidos. Es así como las mujeres toman ventaja -pues dicha cultura de la belleza enfatizaba en "el innato gusto de las mujeres por la belleza" (Peiss, 2011, p. 5)-y se convierten en participantes activas dentro de ella, como inventoras, fabricantes y distribuidoras de productos. Así, entre 1890 y 1924, la población femenina registró más de 450 marcas de preparaciones de belleza en los Estados Unidos, la mayoría de ellas después de 1910 (Peiss, 2011, p. 63).

Este punto en particular es relevante, pues las mujeres no se incorporan en esa cultura de la belleza solo como consumidoras, sino también como productoras; es decir, se involucran de manera directa en la producción de artículos, pasando de elaborar preparaciones caseras de cosméticos y perfumes para consumo propio y para las mujeres de su comunidad, a convertirse en empresarias, masificando y expandiendo geográficamente la venta de sus productos. Tal proceso representa el paso de la receta casera a la receta industrial y, más tarde, a la patente, lo cual no solo forma parte de la modernización del período, sino que también constituye un mecanismo de movilidad social y económico para el sector femenino.

Este cambio se inscribe dentro de otras transformaciones que se están llevando a cabo en el ámbito social, como la vivencia misma de la modernidad por parte de la población femenil que implicaba la toma creciente del espacio público, antes reservado a los varones o a las "mujeres públicas". En tal sentido, la cultura de la belleza no solo hace referencia al surgimiento de la belleza como negocio, como industria, sino también a los nuevos significados que la modernidad introduce en las condiciones sociales de vida de las mujeres, muy cambiantes por cierto todavía en este período (Gourley, 2008; Hill, 2002; Marchand, 2008; Peiss, 2011; Sivulka, 1998, 2001, 2009).

Para ejemplificar las reflexiones anteriores, se va a estudiar de forma breve el caso de cuatro mujeres que impactan de forma significativa a la cultura de la belleza, en tanto productoras de artículos de belleza femenina. Se trata de Annie Turnbo Malone y Madam C. J. Walker -ambas afrodescendientes- y de Elizabeth Arden y Helena Rubinstein. Annie Turnbo Malone (1869-1957) comenzó, alrededor de 1890, a experimentar con productos a base de hierbas, dedicados al cuido del cabello y del cuero cabelludo de las mujeres afrodescendientes (Peiss, 2011, p. 67). Se debe recordar que la población afrodescendiente tenía problema de caída de cabello debido a una dieta deficiente -herencia de la época de la esclavitud-, así como a las malas condiciones sanitarias que no permitían un lavado regular.

Ya para 1900, Turnbo había desarrollado un tratamiento para el cabello basado en hierbas y en enjuagues de huevo, ingredientes de uso común en las 
preparaciones caseras de cosméticos; incluso, llegó a desarrollar una serie de productos de belleza pensados, de forma exclusiva, para las afrodescendientes (The State Historical Society of Missouri. Historic Missourians, s. f.). En 1906, registra su marca como "Poro", nombre de una sociedad religiosa del grupo étnico mendé, situada en África Occidental (Peiss, 2011, p. 67), fundando así la Poro Company. Al finalizar la I Guerra Mundial, se convierte en una pionera de la industria cosmética y de la belleza en los Estados Unidos (The State Historical Society of Missouri. Historic Missourians, s.f.).

Por su parte, Madam C. J. Walker (1867-1919) -cuyo verdadero nombre es Sarah Breedlove- llegó a ser una vendedora de los productos Poro. Era hija de esclavos e, incluso, trabajó en la misma plantación de algodón que sus padres; también fue lavandera. Como Turnbo, sufrió de pérdida de cabello y tuvo problemas constantes en su cuero cabelludo, hasta perderlo por completo. En 1905, realizó varios ensayos con diferentes ingredientes para curar su condición y logró elaborar un ungüento y un sistema de limpieza para recuperar su cabello. Comenzó a vender estos productos a otras mujeres afrodescendientes, primero de manera personal y luego a través de la empresa Walker Company, fundada en 1911 (Bundles, 2012).

Elizabeth Arden (1876-1966) -cuyo verdadero nombre es Florence Nightingale Graham- nació en Canadá. En 1908 se traslada a Nueva York, donde inaugura su primer salón de belleza en la Quinta Avenida, ofreciendo tratamientos de belleza como limpiezas faciales (Durango, 2003 y Léon, 2010). Entre los primeros productos desarrollados por Arden, destacan aquellos especiales para los viajes -cuya venta inicia en 1917- y cremas faciales (PerfumesClub, 2013). Arden acuñó la famosa frase "no hay mujeres feas, sino mujeres que descuidan su belleza", con la que defendía su idea de que toda mujer tenía la posibilidad de lucir bien y, con sus productos, pretendía ayudar a lograrlo.

Finalmente, Helena Rubinstein (1872-1965), de ascendencia judía, nació en Polonia. En 1896 viaja a Australia, donde comienza a desarrollarse en el campo de la belleza, estableciendo en Melbourne, en 1903, la Helena Rubinstein \& Co. Lanza así su primera crema facial elaborada sobre la base de una receta familiar, la cual introduce utilizando el eslogan "la belleza es poder", que le daría fama durante toda su trayectoria. Al estallar la I Guerra Mundial se traslada a vivir a los Estados Unidos y en 1915 abre, en Nueva York, su primer salón de belleza en ese país (L. C., 2011; The Jewish Museum, 2014). Ya para la década de 1920, la "Madame" -como era conocida- se había convertido en una exitosa mujer de negocios, con salones de belleza por todo el mundo.

Ahora bien, ¿por qué es relevante conocer la trayectoria de estas mujeres empresarias en el campo de la belleza? Precisamente para enfatizar el hecho de que, a diferencia de otro tipo de productos, las mujeres no solo son consumidoras, sino también productoras de artículos y que algunas de ellas -como las reseñadas- lograron movilidad social y reconocimiento como empresarias de la 
belleza, en una época en la que tal logro en el espacio público estaba reservado para los hombres. Pero, además, estas evidencian la incidencia del factor étnico unido al de género, pues demuestran que no solo las mujeres blancas fueron exitosas en este ámbito, sino también las afrodescendientes. En este sentido, si bien el ideal de belleza predominante en las primeras décadas del siglo XX -como se estudia en el apartado siguiente- es el de la mujer blanca, las afrodescendientes también incursionaron como empresarias en este ámbito, para solucionar un problema muy concreto de esta población, como lo era la pérdida constante del cabello. De forma distinta, las mujeres "blancas" -como Arden y Rubinstein- lo hacen para "embellecer" más a las mujeres - predominantemente a las "blancas"-, ofreciéndoles una serie de productos a través de los cuales mejorar su apariencia física y lograr cierto "empoderamiento", en un contexto social en el que la belleza física era un elemento básico de la feminidad. Este "blanqueamiento" de la población femenina en particular también se presenta en el caso de Costa Rica, ya que los productos de belleza estaban dirigidos a las mujeres "blancas", cuyas imágenes son las que aparecen en los anuncios publicitarios de estos artículos.

\section{Ideales de mujer y belleza a inicios del siglo $X X$}

En este apartado se van a considerar los ideales de belleza femenina dominantes en los inicios del siglo XX, a partir de dos importantes influencias: las ilustraciones de mujeres y el Art Decó, para luego establecer su influencia en la publicidad costarricense de productos de belleza. A inicios del siglo XX, las publicaciones impresas estadounidenses acostumbraban incluir en sus ediciones ilustraciones de distintos tipos y temáticas. No obstante, en este período, las revistas alcanzan una gran importancia, no solo en número, sino también en cuanto a la cantidad de personas que las leían, adquiriendo particular relevancia las dirigidas al público femenino, sobre todo la Ladie's Home Journal, revista que en el mes de febrero de 1903 alcanza la impresionante cifra de un millón de ejemplares.

Justo en la portada de la revista que anunciaba el logro de tal cifra, aparece la ilustración de una joven mujer, elaborada por el dibujante Charles Dana Gibson. A partir de entonces, Gibson publicó una serie de dibujos de mujeres jóvenes, ya fuera solas o realizando distintas actividades sociales. Dada la calidad y el estilo de sus dibujos de mujeres, estos llegaron a ligarse con su nombre, de ahí que son conocidas como las "Gibson Girls". 
Imagen 1. Distintos rostros de las "Gibson Girls"

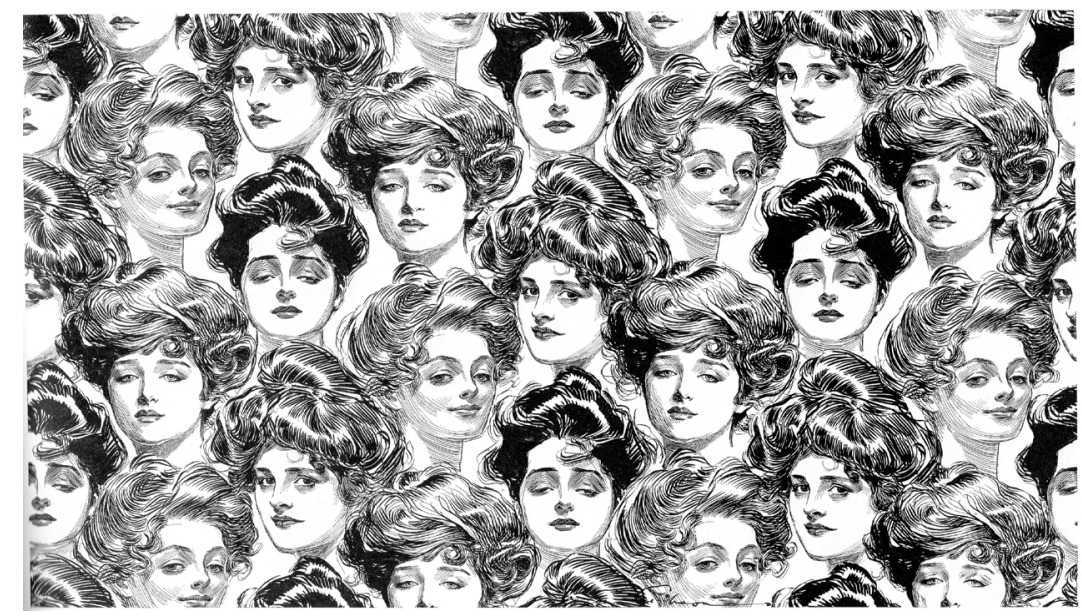

Fuente: Gibson, C. (2013). Eighty Drawings. Including The Weaker Sex: The Story of a Susceptible Bachelor. New York: Dover Publications.

Charles Dana Gibson (1867-1944) fue un artista estadounidense que se hizo famoso con las ilustraciones de mujeres jóvenes, las cuales se publicaron en periódicos y revistas de la época, como Life, pero especialmente en la Ladie's Home Journal, la revista femenina más importante en las primeras décadas del siglo XX. Ahora bien, fue tanta la influencia que llegaron a tener estas ilustraciones de mujeres publicadas en los principales medios de comunicación impresos de la época, que su forma de vestir y de peinarse, e incluso su porte mismo - es decir, la manera en que se las representaba sentadas, de pie o incluso realizando actividades como bailes, cenas, paseos y caminatas por la calle- entre otras, se convirtió en el ideal de belleza de las mujeres y en un símbolo de estatus, ya que era una forma de imitar a las mujeres de la clase alta. Cabe señalar que todos los dibujos de Gibson son de mujeres blancas (Kitch, 2001). En la Imagen 1 se puede apreciar un mosaico de distintas versiones del rostro de estas mujeres.

En términos de esta investigación, interesa resaltar tres aspectos básicos de las "chicas Gibson". El primero de ellos es el uso mismo de la palabra "girls", ya que se les presenta como mujeres jóvenes, como chicas, forma común de referirse a estas mujeres a inicios del siglo XX. Sin embargo, este término coincidía con una creciente incorporación de estas mujeres al ámbito laboral fuera del hogar, por ejemplo, como operadoras en compañías telefónicas o como trabajadoras en las tiendas por departamentos (Gourley, 2008). Al respecto, resulta interesante la comparación con el caso costarricense, pues a las obreras de las primeras décadas del siglo XX se les solía llamar "obreritas", como una forma de infantilizarlas y de minimizar su papel en la sociedad (Mora, 1995).

En segundo lugar, en los dibujos de Gibson, las mujeres aparecen en distintos lugares públicos, generalmente acompañadas de otras mujeres o 
de hombres, aunque también aparecen solas. Se trata, entonces, de mujeres que desafían la visión social predominante acerca del lugar que ocupan en la sociedad, pues, lejos de permanecer en sus hogares, se incorporan al espacio público. Como consecuencia, se necesitó un modelo que les sirviera de guía en ese nuevo espacio y qué mejor "control" que establecer un modelo de belleza que normalizara lo que se debía esperar de estas jóvenes (Gourley, 2008, pp. 27-32).

Por último, ¿qué características tenía la "Gibson Girl"? Físicamente se trata de una mujer alta, bien vestida, con una cintura muy delgada a causa del uso del corsé, un cuello largo como de cisne, un cutis totalmente limpio, libre de cualquier tipo de imperfección como manchas, pecas o espinillas, y una larga cabellera recogida en un moño. A la par de estas características, la chica Gibson se distinguía por su actitud. Se presentaba como una mujer sofisticada, que no permanecía sola en su casa, sino que se desplazaba por lugares públicos y que participaba de diversas actividades sociales a la par de los hombres y de otras mujeres (Gourley, 2008).

El otro elemento que influye en los ideales de belleza y de mujer en las primeras décadas del siglo XX, es el Art Decó, el cual encuentra su apogeo entre las dos guerras mundiales, es decir, entre las décadas de 1920 y 1940. En tal sentido, el Art Decó es una expresión artística muy vinculada con la modernidad, la cual se caracteriza por la innovación, por una decoración sobria, por el uso de nuevos materiales y de formas geométricas como "cuadrado, círculo y triángulo combinadas con las líneas simples o paralelas de formas rectas, onduladas o en zig-zag" (de Mattos, 2002, p. 53). Un ejemplo arquitectónico de esta tendencia artística en Costa Rica es el edificio de la antigua Botica Solera, que se construyó a finales de la década de 1930 y otras edificaciones construidas en Barrio México, situado en la capital josefina (Fonseca, 2008).

Ahora bien, en el Art Decó, como lo apunta de Mattos (2002), la imagen femenina fue importante; presentaba a la mujer como fuerte y joven, "de cabellos cortos, sombrero encasquetado, vestido suelto y portadora de un fino erotismo e intencionalmente provocativa y seductora" (2002, p. 52), además de muy estilizada. En el campo específico de la publicidad, la figura femenina que aparece en los anuncios al estilo Art Decó es cosmopolita y moderna, es decir, es una mujer básicamente urbana o exótica oriental. Asimismo, es importante señalar que tanto la influencia de las "chicas Gibson" como del Art Decó, se puede apreciar en algunos de los anuncios publicitarios sobre productos de belleza del período estudiado, tal y como se explicará en el apartado siguiente. 


\section{Publicidad de productos de belleza femeninos}

Esta sección está dedicada al análisis de los productos de belleza dirigidos a las mujeres, publicitados en los periódicos consultados entre 1900 y 1930. En tal sentido, interesa establecer tres aspectos básicos: los principales artículos de belleza ofertados; las características de su publicidad; el uso de la imagen femenina que se hace en ella -así como las partes del cuerpo de la mujer que se destacan y las concepciones de belleza que se proponen-, con el fin de establecer cuáles eran los modelos de belleza femenina que se transmitían a través de la publicidad en la Costa Rica de las primeras décadas del siglo XX.

Para ello, se estudian tres categorías de productos específicos que en total representan 397 anuncios y que son las que presentan el mayor número dentro de una muestra total de 625 anuncios publicitarios, estudiados a lo largo de una investigación más amplia. Esas categorías son: productos de tocador (276 anuncios), productos para el cabello (98 anuncios) y productos para las uñas (23 anuncios).

Sin embargo, antes de iniciar este análisis, es pertinente establecer algunas de las características que asume la publicidad -en especial la de Estados Unidos, debido a su influencia sobre nuestro país-, durante el período que cubre esta investigación. En primer lugar, es importante señalar que la publicidad es definida por Kotler y Armstrong (2012) como "cualquier forma pagada de representación y promoción no personales acerca de ideas, bienes o servicios por un patrocinador identificado" (p. 436), siendo tres sus objetivos básicos: informar, persuadir y recordar acerca de los productos o de sus empresas, los cuales se llevan a cabo con un "público meta específico, durante un periodo específico" (Kotler y Armstrong, 2012, p. 437).

Desde esta perspectiva, a inicios del siglo XX, se unen dos elementos que favorecen el desarrollo de la publicidad en los Estados Unidos. Por un lado, se produce la consolidación de grandes empresas, de tal forma que entre 1898 y 1902, se pasa de 2653 empresas independientes a 269 compañías, las cuales controlan desde ferrocarriles hasta productos básicos para el desarrollo industrial del momento como el carbón, hierro, cobre, petróleo y acero, así como la producción de azúcar y tabaco. Por otro lado, se produce un fuerte crecimiento poblacional, ya que, mientras los Estados Unidos contaba, en 1860, con 31 millones de personas, para 1920 su población había alcanzado la cifra de 105 millones (Adversiting Age, 2003). Sin duda alguna, ambos elementos alentaron notablemente el auge publicitario, al unirse una oferta creciente de bienes y servicios como consecuencia del desarrollo industrial estadounidense, con un potencial público consumidor también en crecimiento, el cual, incluso, comienza a ser segmentado por la publicidad con el fin de ofrecer bienes específicos para grupos de consumidores y consumidoras particulares. Cabe señalar que, precisamente, como parte de este proceso, las mujeres son "descubiertas" por la publicidad como potenciales consumidoras, situación que se incrementa en la 
década de 1920, época en la que los publicistas daban por aceptado que el 85\% de las compras eran realizadas por mujeres (Adversiting Age, 2003; Sivulka, 1998, pp. 96-97). No en vano, para 1925, el porcentaje de mujeres estadounidenses que trabajaba fuera del hogar era del 25\% (Sivulka, 1998, p. 150).

En las primeras dos décadas del siglo XX, la publicidad estadounidense se caracteriza por el énfasis en la venta al detalle, de ahí la importancia que se le da al empaque de los productos, al uso del color y a las imágenes -básicamente ilustraciones- para llamar la atención del público consumidor, utilizadas en las revistas de la época, características que se intensifican en la década de 1920, sobre todo con el uso del color. Asimismo, los productos relacionados con la higiene y la limpieza personal -como los jabones-y lugares de la casa especialmente dedicados a esas tareas -como los baños-, adquieren relevancia en la oferta publicitaria del período, como parte de la modernidad y de la veracidad científica que se resaltaba en muchos de los productos de la época (Heller, 2005; Sivulka, 1998).

No obstante, la situación anterior cambió con la entrada de los Estados Unidos en la Primera Guerra Mundial. En 1917, muchos fabricantes de productos de consumo cambian su producción y la orientan a la satisfacción de la demanda de bienes que el esfuerzo militar implicaba; de ahí que muchas empresas se limitaran a emplear una publicidad de recordatorio, la cual "ayuda a conservar las relaciones con los clientes y mantiene a los consumidores pensando en el producto" (Kotler y Armstrong, 2012, p. 437). Este es un período caracterizado por las limitaciones en el consumo como consecuencia de la Gran Guerra, aunque la propaganda gubernamental a favor de este conflicto ayudó al mantenimiento de la publicidad mientras este duró.

Concluido el gran conflicto bélico, Estados Unidos experimentó, en la década de 1920, una época de gran prosperidad y de auge del consumismo, alentado por los salarios altos, la publicidad y la disponibilidad de crédito. La oferta y diversificación de bienes y servicios anunciados creció significativamente, a lo que se debe agregar la incursión de un nuevo medio de comunicación: la radio, en el que la publicidad también jugó un papel de primer orden (Adversiting Age, 2003; Heller, 2004; Sivulka, 1998).

Finalmente, las agencias de publicidad se consolidan en este período, experimentando un proceso de profesionalización de sus publicistas y de la publicidad como disciplina, contratando a creativos y a artistas que le "dieron un soplo de aire fresco a una industria con demasiado texto y centrada en los eslóganes" (Heller, 2004, p. 35). Asimismo, estas agencias se expanden a ámbitos internacionales, estableciendo oficinas en Europa e incluso en América Latina. Por ejemplo, la J. Walter Thompson, la principal agencia de los Estados Unidos durante la primera mitad del siglo XX, establece oficinas en Argentina y Brasil en 1929. Este interés por el mercado latinoamericano llevó a que algunas agencias 
publicitarias instauraran departamentos especializados en la traducción y/o redacción de anuncios en español (Mora, 2013; Sivulka, 1998).

Ahora bien, ¿qué ocurría en Costa Rica? ¿Quiénes eran los encargados de realizar la publicidad que se divulgaba en la prensa escrita nacional? En nuestro país no existen agencias publicitarias hasta 1921, cuando se funda la primera de ellas por Alberto H. Garnier, llamada A. H. Garnier \& Co. (Mora, 2013, pp. 58-61). En tal sentido, como lo ha establecido Patricia Vega (2007), dada la situación anterior, los encargados de los periódicos se veían en la necesidad de incursionar en la elaboración misma de los anuncios, ya que la publicidad constituía la principal fuente de financiamiento para los medios de comunicación impresos. Sin embargo, existen dos antecedentes en cuanto a la elaboración de la publicidad que deben considerarse. El primero es la Agencia Universal de Negocios, Comisiones y Publicidad de J. Alabarta y Co., establecida en 1901, la cual se encargaba de confeccionar los anuncios publicitarios para diversos periódicos de la época como La Prensa Libre y La República (Vega, 2007, p. 7). El segundo antecedente se vincula a la presencia de periódicos dedicados, de forma exclusiva, a la publicación de anuncios; tal es el caso de El Agente (1902), propiedad de Constantino Gálvez, así como de El Avisador, el Boletín Comercial y El Anunciador Costarricense (Vega, 2005, p. 133). No es de extrañar, entonces, que los propietarios de estos periódicos de anuncios también se dedicaran a la colocación de los mismos en otros periódicos de la época.

Debido a lo anterior, también resulta muy probable que una parte significativa de los anuncios publicitarios que aparecen en la prensa impresa costarricense durante las primeras décadas del siglo XX, se elaborara fuera del país. Esto se aprecia en aspectos como las imágenes utilizadas, los contextos a los que hacen referencia y los ideales de belleza que representan e, incluso, se publican unos pocos anuncios con fragmentos del texto en inglés o francés o completamente elaborados en esos idiomas. Por ejemplo, en el caso de los anuncios utilizados en esta investigación, en 1912, uno de la crema Pompeya muestra el título en inglés (La Información, 25 de febrero de 1912, p. 7), dos del perfume Divinia están publicados totalmente en idioma inglés (Diario de Costa Rica, 27 de diciembre de 1928, p. 7; 20 de diciembre de 1929, p. 8), mientras que dos anuncios de los perfumes Electra y Caruso, de forma respectiva, presentan partes del texto en francés (La Información, 8 y 10 de noviembre de 1911, p. 3 y p. 6).

Para finalizar el tema relacionado con la publicidad es necesario enfatizar que este ha sido poco estudiado para el caso costarricense, por lo que se tiene muy poca información al respecto. Sobre todo, faltan estudios que aborden la historia de las agencias de publicidad en el país. Establecido el contexto de la publicidad durante el período estudiado, se procederá a analizar cada una de las categorías de productos anteriormente establecidas. 


\section{Productos de tocador}

Esta categoría es la que tiene el mayor número de anuncios con 276, lo cual representa el 69,52\% del total de la muestra. En ella se incluyen varios tipos de productos como cremas, jabones, perfumes, polvos faciales, talcos, depiladores para eliminar el vello y esmaltes para las uñas, cuya característica básica es que, de manera usual, son utilizados por las mujeres, ya sea diariamente o con bastante frecuencia, como parte de su tocador. En el Cuadro 1 se detallan los productos incluidos bajo esta categoría.

Cuadro 1. Productos para el tocador, por subcategorías

\begin{tabular}{|c|c|c|}
\hline \multirow{2}{*}{$\begin{array}{l}\text { SUBCATEGORÍAS DE PRODUCTOS PARA } \\
\text { EL TOCADOR }\end{array}$} & \multicolumn{2}{|c|}{ TOTAL DE ANUNCIOS } \\
\hline & $\mathbf{N}^{\circ}$ & $\%$ \\
\hline Cremas & 97 & 35,14 \\
\hline Jabones & 72 & 26,08 \\
\hline Perfumes & 47 & 17,02 \\
\hline Polvos & 23 & 8,33 \\
\hline Productos para eliminar el vello & 7 & 2,53 \\
\hline Productos para las pestañas & 4 & 1,44 \\
\hline Talcos & 7 & 2,53 \\
\hline Varios & 19 & 6,88 \\
\hline TOTAL & 276 & 100 \\
\hline
\end{tabular}

Fuente: Elaboración propia con base en los anuncios recopilados de los periódicos costarricenses durante 1900-1930.

Imagen 2. Anuncio de la crema Paño-Sana, 1928

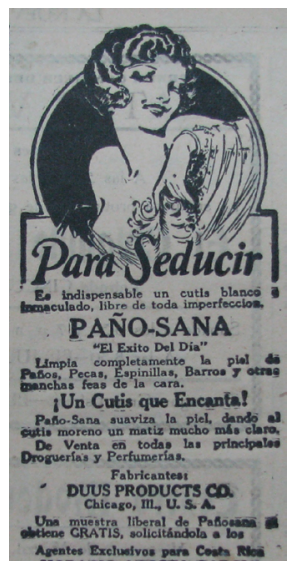

Fuente: La Nueva Prensa,
Dentro de esta categoría de productos, las cremas son las que presentan el mayor número de anuncios con 97, para un 35,14\% del total, pero como lo muestra el Cuadro 2, la oferta de marcas de cremas es amplia en las primeras décadas del siglo XX, si bien aparece poca publicidad de un mismo producto. En general, en los anuncios de cremas tiende a predominar el texto por sobre las imágenes, lo cual no excluye el hecho de que también se presenten imágenes de mujeres, algunas de cuerpo entero, pero, sobre todo, del rostro de ellas, en alusión directa a la parte del cuerpo que impactan más las cremas. Por ejemplo, se localizan desde anuncios en los que predomina el texto, hasta otros más elaborados desde el punto de vista gráfico y de la concepción de la 
idea publicitaria que se busca comunicar, como el de la crema Paño-Sana de 1928 (La Nueva Prensa, 9 de marzo de 1928, p. 7) -Imagen 2-, en el que aparece el rostro de una mujer en posición seductora, dejando ver, incluso, parte de uno de sus senos, acompañado del texto "para seducir. Es indispensable un cutis blanco e inmaculado, libre de toda imperfección" (La Nueva Prensa, 9 de marzo de 1928, p. 7), es decir se vincula la seducción -considerado como un atributo femenino por excelencia- con la presencia de un cutis blanco, limpio y libre de cualquier tipo de imperfección.

Cuadro 2. Cremas, por subcategorías

\begin{tabular}{|l|c|c|}
\hline \multirow{2}{*}{$\begin{array}{c}\text { SUBCATEGORÍAS DE } \\
\text { CREMAS }\end{array}$} & \multicolumn{2}{|c|}{ TOTAL DE ANUNCIOS } \\
\cline { 2 - 3 } & $\mathbf{N}^{\mathbf{0}}$ & $\mathbf{\%}$ \\
\hline Blanco de perlas ideal & 8 & 8,24 \\
\hline Coret & 2 & 2,06 \\
\hline Crema Belleza & 2 & 2,06 \\
\hline Crème Simon & 7 & 7,21 \\
\hline Filoderma & 2 & 2,06 \\
\hline lodex & 2 & 2,06 \\
\hline Magnolia & 3 & 3,09 \\
\hline Melba & 2 & 2,06 \\
\hline Mistinguett & 3 & 3,09 \\
\hline Ninon & 2 & 2,06 \\
\hline Paño-Sana & 4 & 4,12 \\
\hline Pompeyana & 3 & 3,09 \\
\hline Royal & 2 & 2,06 \\
\hline Sirén & 8 & 8,24 \\
\hline Ungüento Blanco y Negro & 3 & 3,09 \\
\hline Ungüento de Doan & 4 & $\mathbf{1 0 0}$ \\
\hline Venus & 3 & 3,12 \\
\hline Varios & $\mathbf{9 7}$ & 38.14 \\
\hline TOTAL & & \\
\hline & 37 & \\
\hline
\end{tabular}

Fuente: Elaboración propia con base en los anuncios recopilados de los periódicos costarricenses durante 1900-1930.

Un aspecto interesante, en el caso de las cremas, es el énfasis en las cualidades blanqueadoras de los productos. En muchos de estos anuncios el efecto de blanquear la piel y dejarla sana de cualquier "imperfección" es uno de los atributos fundamentales; incluso en el anuncio de 1928 antes citado, 
se expresa "Paño-Sana suaviza la piel, dando al cutis moreno un matiz mucho más claro" (La Nueva Prensa, 9 de marzo de 1928, p. 7). Este énfasis en las propiedades blanqueadoras de las cremas es explicable en la medida en que los ideales de belleza femenina que prevalecen en las primeras décadas del siglo XX presentan precisamente esa característica, tal y como se explica en el apartado anterior. Adicionalmente, las marcas de las cremas en sí mismas son naturalizadores de los ideales blancos de belleza: Blanco de perlas ideal, Venus, Magnolia, Pompeyana y Melba.

Un elemento adicional ligado al contexto costarricense debe ser considerado en este punto. Tal y como Palmer $(1995,1996)$ lo ha planteado, desde finales del siglo XIX existe en Costa Rica un pensamiento intelectual que destaca el carácter homogéneo de la población costarricense, en torno al supuesto predominio de la raza blanca, el cual fue sintetizado en el concepto de "auto-inmigración" esbozado por Cleto González Víquez a inicios del siglo XX, el que, entre otras cosas, implicaba aumentar la población al reducir la mortalidad infantil y desarrollar políticas sanitarias por parte del Estado que favorecieran el desarrollo del país. No es de extrañar que, además de la influencia del contexto internacional y, específicamente de la publicidad, la idea de la blancura de la población está presente en el imaginario del país desde inicios del siglo XX, dándose más bien una congruencia entre el ideal de belleza femenina que presentan los anuncios publicitarios y las ideas que sobre la blancura de la población se terminan imponiendo en la sociedad costarricense.

Asimismo, el realce de la belleza natural de las mujeres y una mejor adherencia de los polvos faciales se encuentran entre los principales atributos destacados en la publicidad de las cremas. Sin embargo, es interesante señalar que la prevención, atenuación o eliminación de las arrugas no es el factor principal destacado en la publicidad de este producto y se encuentra presente en pocos de ellos, ligado con la preservación de la juventud. En este punto, la relación con la actualidad resulta relevante, pues el énfasis de los productos de belleza está puesto, en la actualidad, en eliminar las arrugas y conservar una apariencia juvenil.

Un último elemento por señalar es la fabricación nacional de cremas en las boticas o farmacias de la época. En tal sentido, se localizan tres cremas de este tipo: Blanco de perlas ideal, Magnolia y Filoderma, que contribuyen con 13 de los 97 anuncios de la muestra analizada. En el caso de la crema Blanco de perlas ideal, esta es preparada por el farmacéutico Horacio Acosta en 1921 (Diario de Costa Rica, 21 de mayo de 1921, p. 2), mientras que las cremas Magnolia y Filoderma son elaboradas por la Botica Francesa. La primera es una "excelente preparación para embellecer y blanquear el cutis" (La República, 8 de noviembre de 1907, p. 6; La Prensa Libre, 28 de marzo de 1913, p. 4) y, la segunda, es una "magnífica pomada, la mejor que se conoce" (La Prensa Libre, 4 de octubre de 1912, p. 2). 
En la Botica Francesa también se elabora la Crema de primavera, de miel y almendra, de la cual solo se localiza un anuncio (La Información, 17 de junio de 1917, p. 3). Igualmente, solo se localiza un anuncio de la crema Oriental, del año 1914, en el cual se apunta que este producto es preparado en la Botica Oriental "y se vende en todo el país" (La Prensa Libre, 21 de noviembre de 1914, p. 4), ambos ubicados en la subcategoría de varios. En total, se puede determinar en 15 anuncios que las cremas publicitadas son de origen nacional mientras que el resto -82- son importadas. Resulta importante destacar que en la publicidad de las cremas y, usualmente, en la de los anuncios de la industria cosmética de los Estados Unidos y de Europa, hay una fuerte corriente orientalista, posiblemente porque el uso de cremas, perfumes, jabones, ungüentos y otros productos se asocia con propiedades de belleza, así como con cualidades eróticas y exóticas.

Finalmente, en la subcategoría de varios, se ubican anuncios sobre cremas de los que solamente se encuentra un anuncio, para un total de 37 anuncios, cuyas características se ajustan a lo ya apuntado. Los nombres de estas cremas son muy variados y van desde nombres de mujeres como Virginia, Flora y Bella Aurora, hasta otros como Kaloderma, Derma Blanca, Crema de Castilla y Ancla.

Los jabones son el segundo producto con mayor número de anuncios, con un total de 72 , lo que representa el $26.08 \%$ de este tipo de productos, como se observa en el Cuadro 3 . En el caso de los jabones hay una gran variedad de marcas e incluso algunos de los nombres no corresponden todavía a marcas como tales, sino que llevan los nombres de sus creadores, como el Jabón de romero del Dr. Lobb que costaba un colón (La República, 27 de julio de 1905, p. 3), o el Jabón del Dr. Schleich (Diario de Costa Rica, 28 de enero de 1927, p. 3). La publicidad con apellidos extranjeros, además de tener el elemento legitimador de ofrecer productos foráneos cuando se asocia al nombre del doctor, es también un indicador de profesionalismo y modernidad, así como de la presencia de la ciencia en su elaboración, situación que era importante establecer en el campo de la publicidad en las primeras décadas del siglo XX, dada la presencia de personas que ofrecían productos casi mágicos que curaban prácticamente todo tipo de dolencias; de ahí la relevancia que van adquiriendo las marcas como la forma "moderna" de garantizar el respaldo profesional y científico de los distintos productos ofrecidos por medio de la publicidad (Mora, 2013; Sivulka, 1998).

En el caso de los anuncios de jabones, generalmente se destacan sus componentes naturales, su perfume, su carácter antiséptico, su suavidad, su abundante espuma y su capacidad para quitar las imperfecciones de la piel, como las espinillas, los barros y los puntos negros, y devolverle así a la piel su suavidad, su aspecto terso y su apariencia juvenil. A partir de estas líneas generales cada marca busca posicionar sus propias características. 
Para este período sobresalen cinco marcas: Guarias de Turrialba, Heno del Campo, Mármol, Palmolive y Reuter, cuya distribución numérica y porcentual se aprecia en el Cuadro 3. Como se desprende de este cuadro, la marca que posee más anuncios es Heno del Campo con 9, todos localizados en la década de 1920. Esta marca, si bien todavía conserva el nombre de su creador, el Dr. Dralle, se caracteriza por enfatizar en su publicidad los aspectos gráficos por encima del texto; este presenta imágenes del envase del jabón, el cual venía empacado en cajas, por lo general acompañado de la imagen de una mujer joven, algunas veces mirándose en un espejo.

Cuadro 3. Jabones, por subcategorías

\begin{tabular}{|l|c|c|}
\hline \multirow{2}{*}{$\begin{array}{l}\text { SUBCATEGORÍAS } \\
\text { DE JABONES }\end{array}$} & \multicolumn{2}{|c|}{ TOTAL DE ANUNCIOS } \\
\cline { 2 - 3 } & $\mathbf{N}^{\circ}$ & $\%$ \\
\hline Certificado De Ross & 3 & 4,16 \\
\hline Guarias de Turrialba & 6 & 8,33 \\
\hline Heno del Campo & 9 & 12,5 \\
\hline Mármol & 6 & 8,33 \\
\hline Palmolive & 3 & 4,16 \\
\hline Reuter & 8 & 11,11 \\
\hline Varios & 37 & 51,38 \\
\hline TOTAL & $\mathbf{7 2}$ & $\mathbf{1 0 0}$ \\
\hline
\end{tabular}

Fuente: Elaboración propia con base en los anuncios recopilados de los periódicos costarricenses durante 1900-1930.

El hecho de que este jabón enfatice los elementos gráficos no es casual. Su creador, el español Salvador Echeandia Gal, fundó a finales del siglo XIX una fábrica llamada Perfumería Gal, dedicada a la elaboración de "jabones, polvos de arroz, elixires y petróleo Gal” (Centro de documentación publicitaria, 2016), la cual, en 1905, inicia la elaboración del jabón Heno de Pravia, comercializado en Costa Rica con el nombre de Heno del Campo. Adicionalmente, la Perfumería Gal se caracterizaba por la utilización de envases y etiquetas novedosas (Centro de documentación publicitaria, 2016).

El segundo jabón de tocador en importancia numérica es el jabón Reuter, con ocho anuncios, el cual se publicita desde inicios del siglo XX, aunque su publicidad se concentra en la década de 1920. En tal sentido, resaltan los cambios en los anuncios de este jabón, desde aquellos en los que predomina el texto a inicios del siglo XX, hasta los que enfatizan en los aspectos gráficos, incluidas la representación femenina. Cabe destacar que en todos los anuncios del jabón Reuter aparecen uno o dos rostros femeninos, destacando el cabello corto de las mujeres. 
Por su parte el jabón Mármol, con seis anuncios, preparado por el Dr. Schleich, presenta anuncios sencillos, con predominio de texto y sin ninguna imagen femenina, pese a ser anuncios de la década de 1920, mientras que el jabón Guarias de Turrialba es el único que, por su nombre, parece ser nacional, si bien su publicidad no lo especifica. Sus seis anuncios se concentran en el año 1926 y, en general, son bastante sencillos, elaborados solamente a partir de texto y sin ningún tipo de imagen.

En cuanto al jabón Palmolive, este está presente solo con tres anuncios: uno del año 1925 y dos de 1929, situación que extraña un poco, dado que se trata de una reconocida marca de jabones de tocador que surge desde 1898, gracias a Caleb Johnson, quien crea un jabón a base de "aceites de oliva y palma" (Diario de Costa Rica, 8 de agosto de 1925, p. 8), ingredientes de los que deriva el nombre Palmolive y que, además, le dan su color verde (Marcas con historia, 2008). En estos tres anuncios se destacan las cualidades del producto, su empaque y la frescura y el aspecto natural que proporciona al cutis femenino. Adicionalmente, en dos anuncios aparece un rostro de mujer.

El jabón Certificado De Ross - "tan bueno como huele"- también se encuentra presente con tres anuncios. De ellos interesa destacar la presencia de una imagen femenina de cuerpo completo en todos e incluso de dos mujeres desnudas, una totalmente cubierto por una larga cabellera (La Información, 26 de abril de 1919, p. 4) y otra con solo una bata, preparándose para el baño, de la cual se muestra uno de sus senos descubierto (La Información, 27 de abril de 1919, p. 6), ambos del año 1919. Estos anuncios son particularmente significativos, pues el presentar el cuerpo femenino desnudo, no era lo "normal" en la Costa Rica conservadora de las primeras décadas del siglo XX, sobre todo considerando el hecho de que el cuerpo de las mujeres se ligaba directamente con la maternidad y, por ende, con su papel de madres, situación que socialmente llevaba a concebir como inapropiada su exposición pública de cualquier tipo, norma que la publicidad de vez en cuando obviaba.

Finalmente, en la categoría de varios, se ubican 37 anuncios de jabones de los que solo se localizan uno o dos anuncios de cada producto. Al respecto, sobresale la gran variedad de marcas, entre ellas Kaloderma, Vinolia, Filoderma, Mennen, Pears, Jabón de Ross y Élida, entre otros, así como la presencia de alguna imagen femenina en 19 de ellos. Generalmente se muestra el rostro o el torso de las mujeres. Nótese el predominio de marcas extranjeras como Mennen y Pears, así como la presencia de aquellas derivadas de términos griegos como Kaloderma y Filoderma, estas últimas representando un ideal de belleza europeo.

Un último aspecto por destacar en el caso de los jabones, es la presencia de productos preparados en las propias boticas o farmacias de la época. Tal es el caso del Jabón de hiel de vaca elaborado en la Botica Francesa en 1916, 
promocionado como "inmejorable para limpiar el cutis de manchas y pecas" (La Información, 10 de abril de 1916, p. 8).

Por su parte, los perfumes aportan 47 anuncios -17,02\% - a la categoría de productos de tocador, siendo el tercer producto en importancia dentro de la misma. Básicamente se encuentran dos marcas de perfumes bien definidas: L.T. Piver y Divinia. En el caso de la primera, esta presenta ocho anuncios que destacan el envase del producto, o dibujos de flores, en alusión directa a su lema "el perfume de las flores", dada la presencia de extractos de plantas en su elaboración, ello explica la presencia de la imagen femenina en solo dos de los ocho anuncios.

El perfume Divinia con cinco anuncios, también se centra en resaltar las cualidades del producto -como la imagen de su envase- y solo en tres anuncios aparece una imagen de mujer. Sin embargo, un aspecto que resulta ilustrativo del grado de internacionalización de la publicidad mundial y de la costarricense en particular, es que dos de los anuncios están publicados en idioma inglés, uno en 1928 (Diario de Costa Rica, 27 de diciembre de 1928, p. 7) y otro en 1929 (Diario de Costa Rica, 20 de diciembre de 1929, p. 8). Los otros anuncios de perfumes -34 en total-, se caracterizan por la variedad de sus marcas, como Le Pirate, Divina Mentira, Mi Nena y Camia, entre otros, y por la poca presencia de imágenes femeninas en ellos. En general, se trata de una publicidad con poco texto, que enfatiza el envase del producto y sus cualidades, con evidente referencia contextual a París.

Otros artículos que destacan en esta categoría son los polvos con 23 anuncios, para un $8,33 \%$ del total de anuncios en la categoría de productos de tocador. En el caso de este artículo, predominan cinco marcas, aunque con dos o tres anuncios cada una. Ellas son: Beso de novia, Heno del Campo, Melba, Melbaline, Flora, más 12 anuncios varios, en los cuales prevalece el

Imagen 3. Anuncio de polvos Melba, 1926

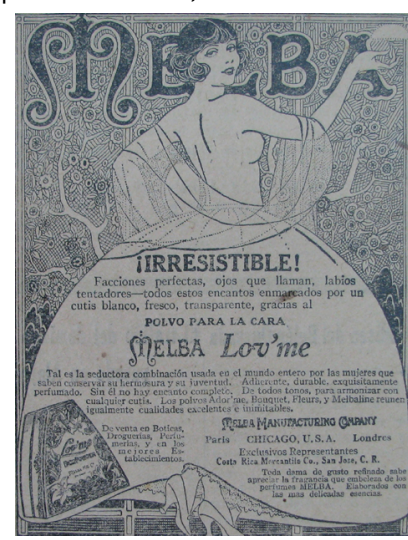

Fuente: La Tribuna, 19 de enero de 1926, p. 6. texto, explicando las cualidades del producto y sus efectos positivos para la cara de las mujeres; incluso, hay poca presencia de imágenes femeninas, de tal forma que no hay mucha diferencia entre un anuncio de polvos faciales de 1908 y uno de 1929.

No obstante, hay algunos anuncios que ya permiten advertir cambios que se presentarán en la publicidad de este producto en las décadas siguientes. Por ejemplo, en un anuncio de polvos Melba publicado en enero de 1926 (La Tribuna, 19 de enero de 1926, p. 6) -Imagen 3-, se muestra una imagen femenina de cuerpo entero en una pose de baile, con su dorso desnudo, dejando ver de manera sutil uno de sus senos, mientras que el vestido sirve de marco para colocar el texto, muy 
al estilo de las primeras tiras cómicas utilizadas en los periódicos sensacionalistas estadounidenses de las últimas décadas del siglo XIX. En dicho texto, se destaca el carácter "seductor" que les brinda a las mujeres el uso de los polvos Melba, bajo el título "ilrresistible!”, pues les ayuda a "conservar su hermosura y su juventud" (La Tribuna, 19 de enero de 1926, p. 6).

Otra publicidad de polvos también presenta la imagen de una mujer seductora. Se trata de un único anuncio de polvos Kaloderma publicado en 1929 (La Nueva Prensa, 25 de noviembre de 1929, p. 7) (Imagen 4), ubicado en la subcategoría de varios. En él se presenta el dorso de una mujer ataviado con un abrigo que le cae sobre su espalda. El estilo de la mujer es "sofisticado", su cara está bien delineada, con unos ojos de mirada perdida y su cabello está cuidadosamente arreglado, además, el efecto de sombra de su rostro le brinda al anuncio una singularidad interesante en el conjunto de la muestra analizada. Destacan, en ambos anuncios, las imágenes de mujeres que dejan ver parte de su dorso desnudo, un elemento de seducción y de erotismo que se encuentra presente ya en este tipo de publicidad, es decir, la visión de la mujer seductora y provocativa, elementos que los productos de belleza contribuyen a establecer

Imagen 4. Anuncio de polvos Kaloderma, 1929

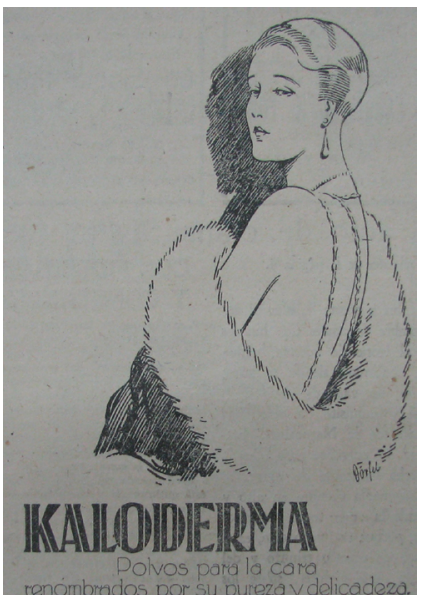

Fuente: La Nueva Prensa, 25 de noviembre de 1929, p. 7. como propios de la feminidad.

En la categoría de polvos, se vuelve a hacer presente la marca Heno del Campo, con dos anuncios que tienen las mismas características publicitarias presentes en el caso de los jabones de esta misma marca. En cuanto a los 11 anuncios restantes que conforman la subcategoría de varios, estos muestran las mismas características antes señaladas, con marcas como Marie Antoinette, Alboderma, La Parisienne y Columbia.

Las siguientes dos categorías son los productos para eliminar el vello y talcos, con siete anuncios cada una, para un 2,53\% de la muestra en cada caso. En cuanto a la primera, se localizan cuatro marcas de este tipo de productos con dos o más anuncios: el depilatorio Novelia que se vende a $\$ 8$ el frasco (Diario de Costa Rica, 27 de marzo de 1928, p. 4) y el "extirpador" Sirén, que se vende en \$3 el frasco al menos desde 1913 (La Prensa Libre, 28 de abril de 1913, p. 2).

Dos depilatorios más presentan solo un anuncio cada uno. Se trata del depilatorio Coret (Diario de Costa Rica, 17 de enero de 1922, p. 5) y del Agua Dixor (La Nueva Prensa, 31 de julio de 1923, p. 3). Al igual que los dos anteriores, estos productos se presentan como inofensivos para la piel de la 
mujer. Por último, los siete anuncios de los productos para eliminar el vello, se caracterizan por el predominio del texto, destacando las cualidades del producto.

Por su parte, en los talcos prevalece la marca Menenn con cuatro anuncios, en los que este producto es presentado para el cuidado de la piel femenina. De esta forma, en los cuatro anuncios aparecen imágenes de mujeres en distintas situaciones de uso del producto. Llama la atención dos anuncios que hacen referencia a la presencia de mujeres en la playa en traje de baño, ya que esta situación era poco común en la Costa Rica de la década de 1920 y más propia de épocas posteriores, específicamente de la década de 1950. En tal sentido, el hecho de poder disfrutar solas en una playa en traje de baño, es parte de la conquista del espacio público que apenas se iniciaba en nuestro país, pero que había logrado avances importantes en otros contextos sociales, como, por ejemplo, los Estados Unidos, en donde incluso ya se celebraban concursos de belleza en los que las participantes aparecían en trajes de baño, los cuales eran patrocinados por las mismas marcas de este tipo de productos (Banet-Weiser, 1999). Los otros tres anuncios de talcos corresponden a los talcos Mavis, Melba y Floradora. En ellos no aparece ninguna imagen femenina y en los dos últimos lo que se destaca es el envase del producto.

En cuanto a los productos para las pestañas, se localizan solamente cuatro anuncios $(1,44 \%)$, dos de ellos corresponden a la marca Sirén, mientras que los otros dos, son de las marcas Benguria y Maybelline. En ellos predomina el texto, aunque en el caso de los dos anuncios de la pestañina Sirén, sí se muestra el rostro de una mujer, destacando sus largas y cuidadas pestañas. Uno de ellos se acompaña del siguiente texto "ojos soñadores. Lánguidos o hechiceros" (Diario de Costa Rica, 15 de agosto de 1929, p. 10). De nuevo, el uso de un producto de belleza se vincula con el carácter conquistador y seductor de los ojos femeninos y con el avivamiento de sus "encantos misteriosos" (Diario de Costa Rica, 24 de agosto de 1929, p. 4).

Es interesante el hecho de que la marca Maybelline se esté introduciendo en el país en 1927, pues, en un anuncio publicado en febrero de ese año, se apunta a que se trata de un "nuevo preparado para embellecer las pestañas" que no produce ningún daño y, por el contrario, resalta "la belleza natural de las pestañas" (Diario de Costa Rica, 25 de febrero de 1927, p. 4). Este cosmético surge en 1915 y su creador es T. L. Williams, quien elaboró un producto para alargar las pestañas y oscurecerlas (Moffett, 2016). En el caso de Costa Rica, es en la década de 1940, cuando la marca de cosméticos Maybelline se publicita masivamente en el país.

Para finalizar la categoría de productos para el tocador, en la subcategoría de varios se tienen 19 anuncios (6,88\%). En ella se ubican aquellos anuncios generales sobre el tema de la belleza que ofrecen "secretos de tocador", los productos de los que solo se localiza un anuncio o aquellos anuncios que se refieren a varios productos a la vez y que, por ende, no son ubicables en una subcategoría específica. 
En términos generales, en la categoría de productos para el tocador, todavía no aparecen los cosméticos como tales, sino una serie de productos para embellecer o proteger el cuerpo femenino como un todo o distintas partes del mismo, en especial el rostro de la mujer, destacando el énfasis en el blanqueamiento de la piel y en la seducción como componentes intrínsecos de la condición femenina, es decir, se trata de una feminidad que está siempre en función de los otros, de los hombres, pues el fin último de la belleza en el caso de las mujeres es lucir atractivas para ellos.

\section{Productos para el cabello}

Esta categoría es la segunda en importancia considerando el número de anuncios recopilados, pues contribuye con 98 anuncios $(24,68 \%)$ al total de la muestra utilizada en este estudio, lo cual denota un particular interés por esta parte del cuerpo femenino en las primeras décadas del siglo XX. En efecto, el cabello se ha concebido tradicionalmente como un elemento de la feminidad, como un aspecto básico del atractivo femenino y, por tanto, su cuidado y arreglo es muestra no solo de buena presencia, sino que se convierte en un elemento para atraer la atención de los hombres, luciendo atractivas para ellos.

Cuadro 4. Productos para el cabello, por subcategorías

\begin{tabular}{|l|c|c|}
\hline \multirow{2}{*}{$\begin{array}{c}\text { SUBCATEGORÍAS DE PRODUCTOS } \\
\text { PARA EL CABELLO }\end{array}$} & \multicolumn{2}{|c|}{ TOTAL DE } \\
ANUNCIOS
\end{tabular}

Fuente: Elaboración propia con base en los anuncios recopilados de los periódicos costarricenses durante 1900-1930. 
Como se aprecia en el Cuadro 4, se localizan nueve productos específicos para el cabello, dentro de los cuales están brillantinas -Brillantina Barcelona-, champús -Mulsified y West-, jabones -Jabón de alquitrán de Parker-, cremas fijadoras -Stacomb-, productos contra la caída del cabello y contra la caspa -Danderine y Tricófero de Barry-, aceites -Nathalina-, lociones capilares -Agua de Abedul y Javol- y "redecillas" y prensas -productos West-; es decir, se trata de una amplia gama de productos que se publicitan en las primeras décadas del siglo XX.

En tal sentido, cabe destacar algunas generalidades presentes en los anuncios de esta categoría. Si bien todavía predomina mucho el texto en ellos, en la gran mayoría de los anuncios se presenta una imagen femenina, enfatizando en el cabello de la misma. No obstante, es llamativo el hecho de que hay anuncios en los que incluso aparecen dos imágenes, ya sea de dos mujeres o de una mujer y un hombre. Por ejemplo, en los nueve anuncios de la Brillantina Barcelona, aparece la misma imagen de un hombre y una mujer, ambos con su cabello bien arreglado, pero con diferente texto.

Igualmente, la crema fijadora Stacomb, suele presentar en su publicidad la imagen de un hombre y una mujer en situaciones que ameritan el visitar un lugar público, como una fiesta o baile, dada la elegancia de ambos. Este mismo producto también presenta anuncios con dos imágenes de mujeres de frente una de la otra, como conversando entre ellas, o bien, se presenta a las mujeres solas, generalmente frente a un espejo o arreglándose en su tocador, en cuyos casos la imagen que se aprecia es la que se refleja en el espejo, como se observa en la Imagen 5.

Un elemento interesante es que cuando aparecen una o varias mujeres, se ubican en un ambiente privado, mientras que, cuando una mujer es acompañada de un hombre, sí se sitúan en espacios públicos, por ejemplo, bailando. Esta situación es propia de la sociedad de la década de 1920, en la cual las mujeres están incursionando con más fuerza en el espacio público, en el caso de los Estados

Imagen 5. Anuncio de la crema fijadora para el cabello Stacomb, 1928

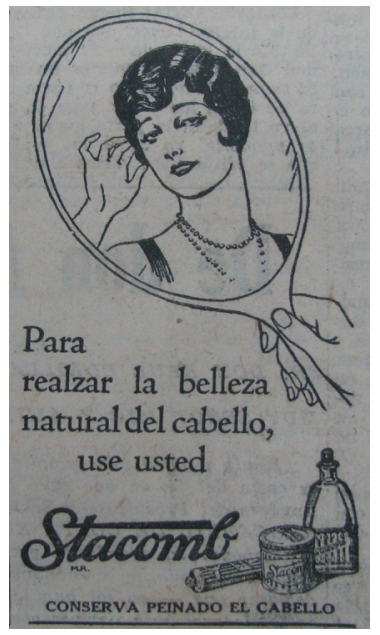

Fuente: La Tribuna, 20 de julio de 1928, p.6. Unidos, mientras que en Costa Rica las mujeres apenas inician una tímida incursión más allá del ámbito familiar, de ahí que, en un primer momento, acompañarse de un hombre en lo público se consideraba como lo propio de las mujeres "decentes" o de las señoritas.

Otro aspecto que destaca en los anuncios de productos para el cabello, es el cambio entre el cabello largo -característico de las mujeres desde el siglo XIX, el de las "Gibson Girls", con su amplia cabellera recogida sobre su cabeza- al cabello corto, que comienza a predominar en la década de 1920. En tal senti- 
do, es sobre todo después de la I Guerra Mundial, que el pelo corto comienza a imponerse entre las mujeres, por considerarse parte del "nuevo modelo de mujer de la época: más independiente, más práctica, con más libertad de movimientos" (Briand y Brian, s. f.). Además, el pelo corto podía usarse de varias formas: ondulado, liso y con tipos de corte distintos (Briand y Brian, s.f.).

Cabe agregar que, en esta época, las artistas de Hollywood se convierten cada vez más en referentes de la moda femenina y al predominar entre ellas el pelo corto, este aspecto también refuerza el predominio de este estilo, no solo como símbolo de libertad de la nueva mujer del siglo XX, sino también de la moda femenina de este período. De hecho, un anuncio del fijador Stacomb, publicado en noviembre de 1928, tenía el sugestivo título "muy siglo veinte", pues "la mujer muy siglo veinte" solo debía usar Stacomb para mantener el cabello sano y atractivo (La Tribuna, 4 de diciembre de 1928, p. 11). Tal evolución está presente en los anuncios de productos para el cabello, pues se nota el paso de anuncios en los que predomina el pelo largo en las mujeres, presente en productos como el Agua de Abedul, Javol y Danderine, hasta el predominio del pelo corto en productos como la Brillantina Barcelona, la crema fijadora Stacomb, el champú Mulsified y el anticaspa Tricófero de Barry.

Un último elemento interesante que aparece en la publicidad de este tipo de productos, es la oferta de los productos West. Si bien se trata solamente de tres anuncios, dos de ellos ofrecen productos poco frecuentes en la publicidad del período estudiado, es decir, accesorios para el cabello, básicamente "redecillas" y "barretas" o prensas para el cabello, mientras que el tercero ofrece el champú West Softex. En el anuncio de "redecillas" publicado en julio de 1921, se especifica que estas "se fabrican a mano con cabello largo; se esterilizan científicamente y son sometidas a un tratamiento especial que las hace excepcionalmente fuertes e invisibles. Se adaptan a cualquier estilo de peinado" (Diario de Costa Rica, 9 de julio de 1921, p. 3), mientras que el anuncio de prensas o "barretas" se publica en agosto de 1921 y en él se expresa que estas "tienen dos fines: sostienen las trenzas, rizos y mechones y facilitan el arreglo del cabello de acuerdo con los últimos estilos" (Diario de Costa Rica, 27 de agosto de 1921, p. 6). También se pueden usar para sujetar el cabello o como prendedores. Sin embargo, adicionalmente se ofrece un novedoso producto: las barretas eléctricas West, de las cuales no se brinda mayor información.

En síntesis, el cabello junto con el rostro femenino, es de las partes del cuerpo sobre las que más se publicitan productos de belleza en la Costa Rica de las primeras décadas del siglo XX, siendo considerado tradicionalmente como un aspecto básico del atractivo femenino. No obstante, el paso del cabello largo al corto evidenciaba algo más que un "simple" cambio físico, convirtiéndose en un símbolo de la libertad femenina y de su incursión creciente en el espacio público. 


\section{Productos para las uñas}

La subcategoría de productos para las uñas está constituida por 23 anuncios $(5,79 \%)$ de un solo producto: el esmalte Cutex, todos publicados en la década de 1920. El primero de ellos es del año 1921 y es hasta 1925 que nuevamente se publican anuncios de este producto. En el anuncio del año 1921, se explican las características de este nuevo producto: "es una serie de productos especialmente preparados para el embellecimiento de las manos. El líquido 'Cutex' suprime radicalmente la cutícula que rodea la base de las uñas y hace innecesario el empleo de instrumentos cortantes que las mutilan" (La Tribuna, 23 de junio de 1921, p. 3). Cabe agregar que este primer anuncio de Cutex está compuesto solamente de texto, siendo el único de los 23 anuncios de esta categoría con ese estilo.

Con la comercialización de Cutex, un producto removedor de cutícula que comenzó a venderse en 1911 (Bennett, 2016), las uñas se convierten en un nuevo centro de atención de la belleza femenina, haciendo extensiva dicha preocupación a la apariencia total de las manos, elemento al que se recurre frecuentemente en la publicidad de este producto. Por ejemplo, se emplean en los anuncios títulos como "si Desea Ud. Bellas Manos, no Debe Descuidar la Cutícula" (Diario de Costa Rica, 15 de setiembre de 1925, p. 9) o "las Uñas Encantadoras son hoy una necesidad social” (Diario de Costa Rica, 19 de setiembre de 1928, p. 7).

Como puede apreciarse, la publicidad de Cutex tiene el fin de posicionar el cuidado de las uñas como un elemento relevante de la apariencia de las manos y en general del cuerpo femenino. Por ello, 22 de los anuncios muestran imágenes de las manos cada vez más estilizadas en la década de 1920. Un elemento importante de destacar es que la publicidad de Cutex tiende a relacionar unas manos bien cuidadas, como acabadas de salir del manicure, con la presencia de las mujeres en el espacio público, en el sentido de que, unas manos con esas características son más presentables ante las demás personas, en especial, ante los hombres, dándoles a las féminas mayor seguridad a la hora de desenvolverse en esos campos, o sea, las manos se convierten en una especie de "carta de presentación" para su inserción en el espacio público, pues como se afirma en un anuncio de febrero de 1926, "las manos siempre están a la vista. ¡Y qué pena da que aparezcan descuidadas, disparejas sus uñas y seca la cutícula de sus bordes" (Diario de Costa Rica, 6 de febrero de 1926, p. 7).

Estos aspectos que enfatiza la publicidad de Cutex, se relacionan con el hecho de que, desde las antiguas civilizaciones de Egipto y China, el cuido de las manos y la costumbre de pintarse las uñas, estaba relacionado con el estatus social de las mujeres, es decir, solo las pertenecientes a las clases altas podían darse el lujo de tener unas manos con esas características, propias de mujeres que no realizaban ningún tipo de trabajo físico, situación que la publicidad de este tipo de artículos busca aprovechar en la década de 1920, de ahí el énfasis en el manicure y en la apariencia bella y agraciada de las manos 
femeninas. No obstante, poco a poco esta visión sufre algunas modificaciones, producto entre otros factores, de los cambios en la condición de lo femenino en los Estados Unidos a partir de la incorporación de las mujeres al trabajo fuera del hogar durante la I Guerra Mundial y al logro del sufragio en 1920, así como a consideraciones meramente comerciales, de tal forma que no solo las damas de sociedad pudieran tener unas manos cuidadas, sino también mujeres que se incorporan al trabajo fuera del hogar, y por ende, al espacio público, en labores como vendedoras y secretarias, aunque por supuesto también amas de casa que podían pagar un servicio doméstico que les permitiera desligarse de las labores hogareñas y mantener unas manos y unas uñas ahora pintadas prácticamente perfectas (Hill, 2002, pp. 97-98).

Un úttimo elemento que interesa destacar en el caso de la publicidad de Cutex es que, como se mencionó antes, el tipo de manos que aparece en estos anuncios es cada vez más estilizado, al estilo del Art Decó; es decir, los dedos son largos y delgados, las uñas son largas y están bien arregladas y pintadas y, por lo general, se acompañan de algún accesorio, ya sea una pulsera o anillos, tal y como se muestra en la Imagen 6. Sin duda, las manos de una mujer ideal, aunque posiblemente no las de la mayoría de las mujeres de la época, sometidas diariamente al laborioso trabajo doméstico.

\section{Reflexiones finales}

Imagen 6. Anuncio de Cutex, 1928

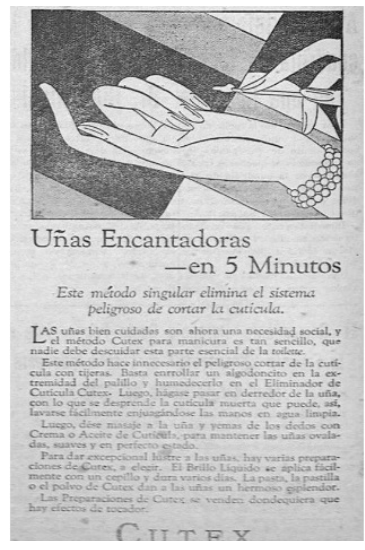

Fuente: Diario de Costa Rica, 12 de setiembre de 1928, p. 2.

Al finalizar esta investigación se van a destacar dos aspectos fundamentales. El primero de ellos se refiere a las características generales de la publicidad de productos de belleza dirigidos a mujeres en las tres primeras décadas del siglo XX. Al respecto, cabe señalar que se trata de una publicidad que destaca las bondades del producto y en la que todavía predomina el texto, en la cual se utiliza mucho la imagen del producto o el distintivo del mismo, aunque se observa una evolución en la publicidad de ciertos productos, que pasan de una publicidad en la que predominan los elementos anteriores, a una que tiende a reducir el texto e incorpora más imágenes tanto del producto como de las mujeres, sector al cual van dirigidos, situación que se da en el transcurso de la década de 1920. Además, París es el referente por excelencia de la moda, sobre todo en productos como los perfumes y en los tratamientos para el cutis, así como también destaca lo oriental, lo exótico y lo extranjero, lo que se aprecia claramente en los mismos nombres de los productos.

Todavía no hay un predominio de las marcas, sino de productos que ya vienen elaborados, pero que todavía tienen un acento "artesanal" en su presentación, o productos de belleza que se pueden preparar fácilmente por las mismas mujeres, e incluso se especifican las recetas de varios de ellos. Tampoco hay presencia toda- 
vía de productos de la gran industria cosmética internacional, salvo la de marcas como Cutex y Maybelline.

En cuanto al uso de la imagen femenina, ésta se utiliza mucho, pero básicamente se destaca la parte del cuerpo sobre la que actúa un determinado producto. Finalmente, hay influencia de las "Gibson Girls" y del Art Decó en los anuncios de este período, destacando el hecho de que las mujeres que aparecen en los anuncios son todas blancas, lo cual es congruente con el impacto de ambas influencias y con el contexto costarricense de la época, además de la presencia de cierto orientalismo.

El segundo elemento es una propuesta de conceptualización del papel de las mujeres en el período estudiado y del lugar de la belleza en él. Para ello se propone el mito de la mujer bella pero fragmentada, el cual se pasa a explicar seguidamente. Las mujeres de las primeras décadas del siglo XX sufren una doble fragmentación: por un lado, la fragmentación física y, por el otro, la fragmentación social.

Físicamente, se da una dicotomía entre la belleza moral y la belleza física. La primera es impulsada desde el discurso religioso que pone a la Virgen María como modelo de mujer y sobre todo de madre, pero que es socialmente aceptado. Cabe recordar en este punto los concursos de belleza moral organizados por la prensa costarricense entre las obreras josefinas en los años 1921 - "Primer certamen de belleza moral" - y 1923 -concurso para elegir la "Delegada de honor de la obrera costarricense" -, en los cuales, más allá de premiar el trabajo de las obreras, "...estos concursos buscan reforzar los valores tradicionales atribuidos socialmente a las mujeres, como la virtud, la castidad y el honor..." (Mora, 2003, p. 201), en un sector de mujeres cuya condición de trabajo fuera del hogar, las hacía particularmente "vulnerables" a la pérdida de dichos valores. En el caso de la belleza física, sin dejar de lado la belleza moral, se plantea que las mujeres pueden y deben preocuparse también por su aspecto físico, incluso como una forma de mantener encendido el "sagrado fuego del hogar." Resulta obvio que esta preocupación por el aspecto físico de las mujeres, es alentado por las concepciones acerca de la "nueva mujer" que surgen al iniciar el siglo XX, una mujer que se concibe más independiente y que poco a poco va incursionando en el espacio público, así como por la cultura de la belleza que se acompaña del surgimiento de la industria de la belleza en el ámbito internacional.

Dicha fragmentación física también se manifiesta en la oferta publicitaria de una serie de productos para cada parte del cuerpo femenino, especialmente para el cabello, la cara y las manos, y además se crea en las mujeres la necesidad de ser bella en todas esas partes, es decir, el cuerpo de las mujeres es un cuerpo que se percibe como fragmentado, pero que al final tiene que ser bello en su totalidad. Asimismo, esta fragmentación se expresa en los productos para regular, hacer crecer o modificar partes de su cuerpo, como por ejemplo el cabello.

Socialmente, las mujeres todavía no son ciudadanas, es decir, no tienen el derecho al sufragio, pero eso no impide que se las conciba ya como potenciales consumidoras. En tal sentido, la publicidad ofrece una serie de productos para cierto sector de mujeres, básicamente de clase media o alta y educadas y, además, se 
presenta una fragmentación étnica en la medida en que las mujeres que aparecen en los anuncios publicitarios son todas mujeres blancas.

De este modo, la sociedad y el modelo de feminidad imperante en las primeras décadas del siglo XX, les exige a las mujeres ser exitosas en tres dimensiones distintas, pero interrelacionadas entre sí y que las fragmentan aún más: como esposas, como madres y como amas de casa. Cabe entonces la pregunta, ¿cuándo van a tener el tiempo y la disposición para ser solo mujeres?

El punto anterior se relaciona con el poco reconocimiento que todavía tienen las mujeres en el espacio público, pues si bien ya están incursionando en él, por medio del trabajo fuera del hogar -como las "chicas" de Gibson o las obreritas costarricenses-, de la educación -especialmente como maestras- y de la participación de un sector de ellas en el movimiento sufragista, por ejemplo en la Liga Feminista fundada en 1923; esta participación no solo es aún escasa, sino que se busca controlar, pues las mujeres que no permanecen en sus hogares, bajo algunas o todas las dimensiones antes descritas, son consideradas casi como "mujeres públicas", mal vistas socialmente y, en el fondo, peligrosas para la misma sociedad, al cuestionar con su accionar, el lugar asignado cultural y socialmente a las mujeres.

Ahora bien ¿cuál es el papel de la cultura de la belleza en estos procesos? La belleza representa un nuevo "mito" o elemento de división entre las mujeres, pues las pone a competir por ser bellas, refuerza el miedo a ser fea y une la importancia de la belleza física con el concepto de "mujer moderna", es decir, una mujer de clase media o alta, que es ama de casa profesional, que además tiene tiempo para educarse -para ser una mejor madre y esposa- sobre todo a través de la lectura de periódicos y revistas y que adicionalmente tiene -o debe tener- tiempo para embellecerse, pues el cuido del cuerpo es parte ahora de la autoafirmación personal y garantía de una mejor inserción en el espacio público, aspectos que la industria cosmética y de la belleza en general contribuirá a profundizar.

Desde esta perspectiva, la cultura de la belleza refuerza en las mujeres el miedo a ser feas, de ahí la relación que se hace entre belleza igual a perfección física, y fealdad igual a imperfección, que en este caso haría alusión al hecho de hacer todo lo necesario para tener un cuerpo perfecto, es decir, una cara sin manchas, pecas o espinillas, unas pestañas largas y bien pintadas, un cabello largo -puede ser recogido al estilo de los moños de las "Gibson Girls"- sano, sin caspa y ondulado, unas manos arregladas y con las uñas sin cutícula y pintadas y un busto rellenito o grande y, si se puede, un cuerpo delgado con una cintura pequeña.

Como se puede apreciar, el logro de tal ideal de belleza además de difícil y laborioso, fragmenta a las mujeres, física y socialmente, por ello la pertinencia del mito de la mujer bella pero fragmentada, o sea, puede que se llegue a cumplir con algunos -o todos-, los lineamientos establecidos por el modelo de belleza imperante, pero ¿a qué costo? Al costo de una mujer que sufre una gran fragmentación en su propio cuerpo y que no tiene todavía el control del mismo. 
Finalmente, resulta interesante e irónico que sea el "tan temido" espacio públi$\mathrm{co}$, el que termine uniendo a las mujeres en tanto experiencia de libertad, de independencia y de cuestionamiento del papel que se les ha asignado socialmente. Al fin y al cabo, como lo señala un anuncio publicado en 1927, "¿qué es la Belleza? LA BELLEZA [sic], es toda la mujer..." (La Tribuna, 22 de marzo de 1927, p. 5).

\section{Referencias}

Adversiting Age. (2003). History: 1910-1920. Recuperado de http://adage.com/article/adage-encyclopedia/history-1910-1920/99072/

Banet-Weiser, Sarah. (1999). The Most Beautiful Girl in the World. Beauty Pageants and National Identity. California: University of California Press.

Bennett, James. (2016). Cosmetics and skin. Northam Warren. Recuperado de http://www.cosmeticsandskin.com/companies/northam-warren.php\#

Briand, Gustavo y Briand, Pablo. (s.f.). La historia del mundo del cabello. El cabello en el siglo XX. Recuperado de http://thehistoryofthehairsworld.com/el_cabello_en_el_siglo20.html

Bundles, A'Lelia. (2012). C. J. Walker: Brillante para los negocios y la filantropía. AllP digital. Recuperado de http://iipdigital.usembassy.gov/st/spanish/publication/2 012/02/20120210145318x0.510017.htm\#axzz43OU2Xr6G

Centro de documentación publicitaria. (2016). La historia de la publicidad. Protagonistas. Salvador Echeandia Gal. Recuperado de http://www.lahistoriadelapublicidad.com/protagonista-310/salvador-echeandia-gal

de Mattos Alvarez, María Dulce. (2002). Del art nouveau al art deco. Casa del Tiempo, 46-53. Recuperado de http://www.uam.mx/difusion/revista/nov2002/ demattos.pdf

Durango, L. (2003). Pioneras de la belleza moderna. El Universal. México. Recuperado de http://archivo.eluniversal.com.mx/estilos/30662.html

Fonseca Calvo, María Eugenia. (2008). Barrio México, el distrito decó de San José. Crisol, 20, 7-8. Recuperado de https://odi.ucr.ac.cr/medios/documentos/crisol/ revista_crisol_20.pdf

Gibson, Charles Dana. (2013). Eighty Drawings. Including The Weaker Sex: The Story of a Susceptible Bachelor. New York: Dover Publications.

Gourley, Catherine. (2008). Gibson Girls and Suffragists. Perceptions of Women from 1900 to 1918. Minneapolis: Twenty-First Century Books.

Heller, Steven. (2004). Los años veinte. Venta de productos: anuncios en la era del jazz. En Jim Heimann (ed.), All-American Ads 20's (pp. 34-37). Madrid: Taschen. 
Heller, Steven. (2005). Seduciendo al nuevo consumidor. En Jim Heimann (Ed.), All-American Ads 1900-1919 (pp. 34-37). Madrid: Taschen.

Hill, Daniel. (2002). Advertising to the American Woman 1900-1999. Columbus: Ohio State University Press.

Kitch, Carolyn. (2001). The Girl on the Magazine Cover. The Origins of Visual Stereotypes in American Mass Media. Carolina: The University of North Carolina Press.

Kotler, Philip y Armstrong, Gary. (2012). Marketing (14a. ed.). México: Pearson Educación. Recuperado de https://profdariomarketing.files.wordpress. com/2014/03/marketing_kotler-armstrong.pdf

L., Carolina. (2011). La historia de Helena Rubinstein, la mujer que inventó la belleza. Recuperado de http://belleza.trendencias.com/cremas/la-historia-de-helenarubinstein-la-mujer-que-invento-la-belleza

León, Eugenia. (2010). Elzzabeth Arden cumple 100 años al servicio de la belleza. Recuperado de http://bellezaenvena.com/2010/07/elizabeth-arden-cumple-cien-anos-al/

Marcas con historia. (2008). Colgate-Palmolive. Recuperado de http://www.marcasconhistoria.com.ar/detalle_palmolive.php

Marchand, Roland. (1986). Advertising the American Dream. Making Way for Modernity, 1920-1940. California: University of California Press.

Moffett, Tamara. (2016). Acerca de Maybelline. eHow en español. Recuperado de http://www.ehowenespanol.com/acerca-maybelline-sobre_338515/

Mora Carvajal, Virginia. (1995). Las luchas de las obreras urbanas en Costa Rica (1900-1930), Nueva Sociedad, 135, 138-149.

Mora Carvajal, Virginia. (2003). Rompiendo mitos y forjando historia: mujeres urbanas y relaciones de género en Costa Rica a inicios del siglo XX. Alajuela: Museo Histórico Cultural Juan Santamaría.

Mora Carvajal, Virginia. (2013). El desarrollo de las agencias de publicidad y su relación con el caso costarricense (1900-1950). Reflexiones, 92(2), 43-63. Recuperado de http://www.reflexiones.fcs.ucr.ac.cr/images/edicion_92_2_A/04-MORA.pdf

Palmer, Steven. (1995). Hacia la "auto-inmigración". El nacionalismo oficial en Costa Rica 1870-1930. En Arturo Taracena y Jean Piel (Coords.), Identidades nacionales y Estado moderno en Centroamérica (pp. 75-85). México: FLACSOEUCR. Recuperado de http://books.openedition.org/cemca/3218

Palmer, Steven. (1996). Racismo intelectual en Costa Rica y Guatemala, 1870-1920. Mesoamérica, 31, 99-121. Recuperado de https://dialnet.unirioja.es/descarga/ articulo/2466989.pdf 
Peiss, Kathy. (2011). Hope in a Jar. The Making of America's Beauty Culture. Philadelphia: University of Pennsylvania Press.

PerfumesClub. (2013). Elizabeth Arden: mucho más que una marca de cosmética. Recuperado de http://blog.perfumesclub.com/elizabeth-arden-mucho-masque-una-marca-de-cosmetica/

Sivulka, Juliann. (1998). Soap, Sex, and Cigarettes. A Cultural History of American Advertising. Belmont: Wadsworth Publishing Company.

Sivulka, Juliann. (2001). Stronger Than Dirt. A Cultural History of Adversiting Personal Hygiene in America, 1875 to 1940. New York: Humanity Books.

Sivulka, Juliann. (2009). Ad Women. How They Impact What We Need, Want, and Buy. New York: Prometheus Books.

The Jewish Museum. (2014). Helena Rubinstein: Beauty Is Power. New York. Recuperado de http://thejewishmuseum.org/exhibitions/helena-rubinstein-beautyis-power\#about

The State Historical Society of Missouri. Historic Missourians. (s.f). Annie Tumbo Malone. Recuperado de http://shs.umsystem.edu/historicmissourians/name/m/malone/

Vega Jiménez, Patricia. (2005). La prensa costarricense en tiempos de cambio (1900-1930). Revista de Ciencias Sociales, 108, 121-144. Recuperado de http://163.178.170.74/wp-content/revistas/108/09-VEGA.pdf

Vega Jiménez, Patricia. (2007). El reinado de la publicidad. Historia de la publicidad en los periódicos en Costa Rica 1900-1930. En Patricia Vega (Comp.), Encrucijadas de la comunicación (pp. 3-31). San José: Editorial Universidad de Costa Rica.

Vega Jiménez, Patricia. (2008). Estrategias publicitarias en Costa Rica (1900-1930). Pensar la Publicidad, 2(1), 45-78. Recuperado de http://revistas.ucm.es/index. php/PEPU/article/download/PEPU0808120045A/15524

\section{Fuentes documentales de las imágenes utilizadas}

Diario de Costa Rica, 12 de setiembre de 1928, p. 2.

La Nueva Prensa, 9 de marzo de 1928, p. 7.

La Nueva Prensa, 25 de noviembre de 1929, p. 7.

La Tribuna, 19 de enero de 1926, p. 6.

La Tribuna, 20 de julio de 1928, p. 6. 